\title{
Association between surgical technique, adhesions and morbidity in women with repeat caesarean section: a retrospective study in a rural hospital in Western Tanzania
}

\author{
R. Mooij ${ }^{1} 2^{*}$ (D, I. H. Mwampagatwa ${ }^{3}$, J. van Dillen ${ }^{4}$ and J. Stekelenburg 5,6
}

\begin{abstract}
Background: The worldwide incidence of birth by Caesarean Section (CS) is rising. Many births after a previous CS are by repeat surgery, either by an elective CS or after a failed trial of labour. Adhesion formation is associated with increased maternal morbidity in patients with repeat CSs. In spite of large-scale studies the relation between the incidence of adhesion formation and CS surgical technique is unclear. This study aims to assess maternal and neonatal morbidity and mortality after repeat CSs in a rural hospital in a low-income country (LIC) and to analyse the effect of surgical technique on the formation of adhesions.
\end{abstract}

Methods: A cross-sectional, retrospective medical records study of all women undergoing CS in Ndala Hospital in 2011 and 2012.

Results: Of the 3966 births, 450 were by CS (11.3\%), of which 321 were $1^{\text {st }} C S, 802^{\text {nd }} C S, 363^{\text {rd }} C S, 124^{\text {th }}$ and one $5^{\text {th }}$ CS $(71,18,8,3$ and $0.2 \%$ respectively). Adhesions were considered to be severe in $56 \%$ of second CSs and $64 \%$ of third CSs. In $2^{\text {nd }} \mathrm{CSs}$, adhesions were not associated with closure of the peritoneum at $1^{\text {st }} \mathrm{CS}$, but were associated with the prior use of a midline skin incision. There was no increase in maternal morbidity when severe adhesions were present. Adverse neonatal outcome was more prevalent when severe adhesions were present, but this was statistically non-significant (16\% vs $6 \%)$.

Conclusions: Our results give insight into the practice of repeat CS in our rural hospital. Adhesions after CSs are common and occur more frequently after midline skin incision at $1^{\text {st }} \mathrm{CS}$ compared to a transverse incision. Reviewing local data is important to evaluate quality of care and to compare local outcomes to the literature.

Keywords: Caesarean section, Tissue adhesions, Outcome, Trial of labour

\footnotetext{
* Correspondence: r.mooij1983@gmail.com

'Ndala Hospital, 15, Ndala, Tanzania

2Jeroen Bosch Hospital, Henri Dunantstraat 1, 5223 GZ 's-Hertogenbosch, The Netherlands

Full list of author information is available at the end of the article
}

(c) The Author(s). 2020 Open Access This article is licensed under a Creative Commons Attribution 4.0 International License, which permits use, sharing, adaptation, distribution and reproduction in any medium or format, as long as you give appropriate credit to the original author(s) and the source, provide a link to the Creative Commons licence, and indicate if changes were made. The images or other third party material in this article are included in the article's Creative Commons licence, unless indicated otherwise in a credit line to the material. If material is not included in the article's Creative Commons licence and your intended use is not permitted by statutory regulation or exceeds the permitted use, you will need to obtain permission directly from the copyright holder. To view a copy of this licence, visit http://creativecommons.org/licenses/by/4.0/. The Creative Commons Public Domain Dedication waiver (http://creativecommons.org/publicdomain/zero/1.0/) applies to the data made available in this article, unless otherwise stated in a credit line to the data. 


\section{Background}

Caesarean section is the most commonly performed abdominal surgical procedure, and the incidence is rising worldwide $[1,2]$. The percentage of births by Caesarean Section (CS) is low in the eastern and southern African region $(6.2 \%)$, but there is a large variation between and within African countries [1,3]. In the case of previous CS, sometimes CS is the only option offered, but in most settings, women can either choose an elective CS or a trial of labour (TOL) [4]. In low-income countries (LICs), both the risks of TOL as well as the risks of repeat CS are increased compared to high-income countries [5-8]. Maternal mortality after CS in Africa is 50 times higher than in high-income countries (HICs), mostly due to anaesthesia complications and haemorrhage $[9,10]$. The most feared complication of TOL is uterine rupture (UR), which occurs in $0.47 \%$ of women who have a TOL [11]. In low-income countries, UR is reported to occur in up to $6.7 \%$ of cases, but these numbers are not reliable since these studies describe only inhospital deliveries and do not report population data $[12,13]$. Adhesion formation after surgery can be the cause of chronic pain and infertility; both common longterm maternal morbidities after CS, as well as a reason for readmission and repeated surgery [14]. Adhesions are associated with both a longer operation time and intra-operative morbidity such as bladder lesions [14, 15]. In subsequent pregnancies, the advantages of vaginal birth after CS (VBAC) are more relevant, since the risks of UR and abnormal placentation increase with the number of previous CS [16]. In many African countries, the total fertility rate (TFR) is high, making VBAC after previous $\mathrm{CS}$ an essential strategy in reducing the rising rate of CSs and its associated morbidities [17]. Rates of VBAC vary between 38 and $48 \%$ across African countries and hospitals $[13,17,18]$.

Internationally, there is debate concerning surgical CS techniques and adhesion formation. Two large metaanalyses examined closure of the visceral peritoneum and reported opposite conclusions [19, 20]. In Ndala Hospital, Tabora Region, Tanzania, different surgical techniques for CS are in use, which are closure and nonclosure of the visceral peritoneum. We performed a retrospective study to assess maternal and neonatal morbidity and mortality after repeat CS in this rural hospital in an LIC and evaluated the effect of surgical technique on the formation of adhesions.

\section{Methods}

\section{Setting}

This study was done at Ndala Hospital, a faith-based hospital, situated in a rural part of Western Tanzania in the Tabora region. The prevalence of CS in this region, as reported in the Tanzania demographic and health survey, was $2.7 \%$ in $2015-2016$ [21, 22]. In the Tabora region, $54 \%$ of deliveries were assisted by a skilled birth attendant (country average: 64\%), and the regional TFR was 6.7 (country average: 5.2) [22].

The hospital serves a catchment area of approximately 200,000 people. Annually, there are roughly 2200 births in the hospital. There is no maternity waiting home. Both basic and comprehensive emergency obstetric care are available. The foetal condition is monitored by intermittent auscultation. Standardised operative reports for CS were introduced in 2010 and include the indication for surgery, previous CS (and number) and a brief section about the presence of adhesions. These were added to the patient's record after surgery.

Most women with one previous $\mathrm{CS}$, without an indication for a CS or contra-indication for VBAC, choose TOL. Internationally, most contra-indications for TOL are relative and not absolute [23]. Contra-indications for TOL in Ndala Hospital consisted of a non-cephalic presentation, and an elective CS recommended by the surgeon at the time of the previous CS (for example due to a uterine rupture or a classical incision, Table 2). In women with more than one previous CS, elective repeat CS is performed, unless the woman requests TOL or presents in the $2^{\text {nd }}$ stage of labour.

\section{Participants}

All women undergoing CS in Ndala Hospital between March 2011 and December 2012 were analysed. Patients with a CS were identified using the operating theatre logbook. The delivery logbook was used to obtain information on neonatal outcomes. To assess the relationship between surgical technique and adhesions, for all $2^{\text {nd }}$ and $3^{\text {rd }} \mathrm{CSs}$, patient records and operative reports were analysed for demographics, indication for CS, whether bilateral tubal ligation was done, and maternal and neonatal outcome. Presence and severity of adhesions were scored in the standardised operative report and divided into "severe" or "minor or no" adhesions, according to the subjective assessment of the operating doctor. If the previous CS was conducted in Ndala and the records were complete, surgical technique (closure of which layers) during prior CS was noted. CSs were divided in elective and emergency procedures. Elective CS was defined as a CS planned before the start of labour and emergency CS was chosen when the decision was made after the onset of labour (or after TOL). Adverse perinatal outcome was defined as a low Apgar score $(<7$ at $\left.5^{\prime}\right)$, including stillbirth [24].

\section{Statistical analysis}

Data management was done using Microsoft $^{\oplus}$ Office Excel $^{\circ}$ 2007; statistical analysis was done with Epi Info ${ }^{\mathrm{Tm}}$ 7 (Centers for Disease Control). First and second repeat 
CS were compared to each other and CS with minor adhesions were compared to CS with severe adhesions. $P$ values were calculated with Fisher's exact tests, T-tests and Kruskal-Wallis tests, as appropriate for the data type and distribution.

\section{Results}

Among the 3966 women who gave birth in the hospital during the 22-month study period, there were $450 \mathrm{CSs}$ $(11.3 \%)$ of which $321(71 \%)$ were $1^{\text {st }}$ CS, $80(18 \%)$ were $2^{\text {nd }} \mathrm{CS}, 36(8 \%)$ were $3^{\text {rd }} \mathrm{CS}, 12(3 \%)$ were $4^{\text {th }}$, and one was a $5^{\text {th }}$ CS $(0.2 \%)$. In $99 \%$ of patients $(115 / 116)$ who underwent a $2^{\text {nd }}$ or $3^{\text {rd }} \mathrm{CS}$, presence and severity of adhesions were reported. Adhesions were considered to be severe in $56 \%(44 / 79)$ of $2^{\text {nd }}$ CS and in $64 \%(23 / 36)$ of $3^{\text {rd }} \mathrm{CS}(p=0.08)$. For $1^{\text {st }} \mathrm{CS}$, the skin incision was more often transverse when operated in Ndala, compared with those who underwent surgery in other hospitals: $71 \%$ $(54 / 76)$ vs $8 \%(3 / 38), p<0.01$. The baseline characteristics of women with repeat CS (data for $2^{\text {nd }}$ and $3^{\text {rd }}$ CS only) are shown in Table 1.

Adverse perinatal outcomes were observed more often $(12 \%$ vs $0 \%, p=0.02)$ in women with $2^{\text {nd }}$ CS than $3^{\text {rd }}$ CS. Thirty-eight of 49 women (78\%) who were booked for an elective repeat CS were in labour before the planned surgery. Adverse neonatal outcome was more common when severe adhesions were present (16\% vs $6 \%)$, but this was not statistically significant ( $p=0.14$, Table 2$)$. A transverse skin incision was statistically significantly associated with fewer adhesions than a midline incision.

Of the 13 cases with multiple repeat CS (12 women with a $4^{\text {th }} \mathrm{CS}$, one with a $5^{\text {th }} \mathrm{CS}$ ), all neonates had Apgar scores above seven at $5 \mathrm{~min}$, and no neonatal or severe acute maternal morbidity or mortality was recorded.

\section{Discussion}

In this rural hospital in an LIC, severe adhesions after CS are common. Adverse neonatal outcome is observed in $12 \%$ of $2^{\text {nd }} \mathrm{CS}$, while this was not the case in $3^{\text {rd }} \mathrm{CS}$. Half of the patients had a midline incision during their first CS, which was associated with severe adhesions.

The majority of patients (78\%) who were booked for an elective repeat CS were in labour before the planned surgery. This has been described in a study from Uganda as well [4]. No data were collected on the scheduled surgery date, and it is unclear if the women did not come for their surgical appointment, or if labour started beforehand. The first could be because women who prefer vaginal birth are afraid they are not allowed a TOL in the hospital and deliberately arrive late, with higher risk of adverse outcome $[4,25]$. The latter could be explained by the fact that no reliable gestational age was available and the planned CS was intentionally planned late to prevent accidental iatrogenic preterm birth. The statistically lower incidence of adverse perinatal outcome in $3^{\text {rd }}$ CS ( $0 \%$ compared to $12 \%$ in $2^{\text {nd }}$ CS, $\left.p=0.02\right)$ suggests when when they are advised not to have a TOL, women present in time.

We observed a high incidence of adverse perinatal outcome after $2^{\text {nd }}$ CSs $(12 \%)$. This might reflect the high general perinatal mortality rate in emergency CSs in a low-resource setting, which has been reported to be up to $19 \%$ [26]. In our hospital the perinatal mortality in $1^{\text {st }}$ CSs is unknown. The aim of this study was to evaluate surgical techniques in CS, but our research has also provided insight in the practice of TOL and repeat CS. Because of the risk of selection bias and without information on successful VBAC rates, this study is not suited to address the risks and benefits of elective CS vs TOL. However, the finding of such a high incidence of adverse perinatal outcomes in $2^{\text {nd }}$ CS (after TOL) warrants further research into the practice of TOL in our hospital. A new study to assess the safety of TOL after a previous CS in Ndala Hospital has already started.

This study found a prevalence of $56 \%$ of severe adhesions after the first CS. This is similar to findings of a recent study in Ghana [27]. Adhesions are a recognised cause of maternal morbidity and a frequent finding in repeat CS [28]. The relationship between adhesions and surgical technique was only examined in women with a $2^{\text {nd }}$ CS. Because of the smaller number of higher order repeat CS, as well as different techniques used in previous CS, finding an association was not possible for this group.

In many studies, maternal and perinatal mortality are not significantly different in women with or without adhesions. Adhesiolysis increases the time to delivery of the child and makes the costs significantly higher [2931]. These studies were conducted in HICs, with a low general perinatal mortality, and CS were performed by medical specialists under optimal conditions. In LICs, the consequences of adhesions could be more severe, which can explain the trend we found towards a higher neonatal mortality rate.

Many studies have been conducted to identify ways to prevent adhesions by assessing surgical techniques, as well as pharmacotherapeutic "adhesion barriers" [32, 33]. Whether closure of the peritoneum during CS affects (reduces or increases) the incidence of adhesions is still debated $[19,20]$. Reviews are based on uncontrolled prospective and retrospective studies. Long-term results of the Coronis RCT reassuringly showed no difference in any outcomes related to adhesions (such as chronic pain and infertility) after closure or non-closure of the peritoneum [34]. Long-term results of the CAESAR RCT are expected as well [35]. In the meantime, arguments for non-closing are the shorter operating time and the use 
Table 1 Characteristics of women with repeat CS

\begin{tabular}{|c|c|c|c|}
\hline \multicolumn{4}{|l|}{ Operative characteristics } \\
\hline Median estimated blood loss & $150(100-300)$ & $225(150-300$ & 0.98 \\
\hline (ml, interquartile range) & $(n=78)$ & $(n=36)$ & \\
\hline Classical incision in uterus & $1(1 \%)$ & $2(6 \%)$ & 0.23 \\
\hline Inadequate lower segment & $15(19 \%)$ & $10(28 \%)$ & 0.27 \\
\hline Total number tube ligation & $26(33 \%)$ & $27(75 \%)$ & 0.01 \\
\hline \multicolumn{4}{|l|}{ Skin incision } \\
\hline Midline & $36(45 \%)$ & $25(69 \%)$ & 0.01 \\
\hline Transverse & $43(54 \%)$ & $11(31 \%)$ & 0.02 \\
\hline Combined (T-incision) & $1(1 \%)$ & 0 & 0.69 \\
\hline Adhesions (total) & $n=79$ & $n=36$ & \\
\hline Minor & $35(44 \%)$ & $23(64 \%)$ & 0.08 \\
\hline Severe & $44(56 \%)$ & $13(36 \%)$ & \\
\hline Neonatal outcome & $n=82$ & $n=32$ & \\
\hline Stillbirth & $8(10 \%)$ & 0 & 0.05 \\
\hline Child alive, Apgar score $<7$ at $5^{\prime}$ & $2(2 \%)$ & 0 & 0.48 \\
\hline $\begin{array}{l}\text { Adverse neonatal outcome } \\
\text { (stillbirth and Apgar score }<7 \text { at 5) }\end{array}$ & $10(12 \%)$ & 0 & 0.02 \\
\hline Hospital previous CS & $n=80$ & $n=72$ & \\
\hline Ndala & $57(71 \%) 4$ & $8(67 \%)$ & 0.54 \\
\hline Other hospital & $23(29 \%)$ & $21(29 \%)$ & 0.95 \\
\hline Unknown & 0 & $3(4 \%)$ & 0.10 \\
\hline
\end{tabular}

of less suture material. Still, if closing the peritoneum reduces adhesions, this investment could easily be worthwhile. This is why some authors have already argued for the closure of the peritoneum [36]. In our retrospective study, there was no association between the closure of the peritoneum and the presence of adhesions.

The difference in the type of incision between patients operated in Ndala Hospital and other hospitals highlights the generally low rate of transverse incisions in LICs [37]. Ndala Hospital has regularly had foreign doctors performing and teaching CS using Pfannenstiel or Misgav-Ladach techniques with a transverse incision [38]. In Tanzania, many domestically educated doctors are only trained in performing CS with subumbilical midline incisions. This explains the difference in $1^{\text {st }} \mathrm{CS}$ techniques found in this study (71\% transverse incisions for CSs performed in Ndala, $8 \%$ when CS was performed elsewhere). The WHO advises midline incision because it is easier when using local anaesthesia [39]. However, transverse incisions have been shown beneficial for different short-term outcomes (such as pain and wound infection) in a low-resource setting [40]. RCTs in general surgery have shown an increased risk of incisional hernias in midline incisions [41]. For this, as well as for cosmetic reasons, transverse skin incision could be the technique of choice [37]. To our knowledge, no studies have examined adhesion formation following different CS skin incisions. In our research, we found significantly fewer adhesions after a previous transverse incision.

In this retrospective study, the significantly higher maternal age at second CS in women with severe adhesions could be either a finding due to bias or a biological effect. Recently, another large study has also found an increase in adhesion formation in women $\geq 35$ years (adjusted odds ratio 1.28, 95\% CI: 1.05-1.55) [42].

\section{Study limitations}

There could be confounding by indication, as doctors could decide for themselves whether to close the peritoneum and observation bias in recognising and noting adhesions. The presence and subjective severity of adhesions was a regular part of the operating report. We stratified the presence of adhesions in two groups, without details of the location or a more precise grading, such as has been used in prospective studies [43]. Another bias could be caused by women with many adhesions being less likely to become pregnant. Since most midline incisions were done in other hospitals, different patient and doctor characteristics could be a confounder for the increased number of adhesions after a midline incision CS. Information on perinatal outcome is limited to the Apgar score at $5 \mathrm{~min}$ without knowledge of the 
Table 2 Severity of adhesions in second $\mathrm{CS}^{\mathrm{a}}$

\begin{tabular}{|c|c|c|c|}
\hline Median age (yrs, interquartile range) & $22(20-26)$ & $25(20-30)$ & 0.04 \\
\hline Median blood loss (ml, interquartile range) & $150(100-400)$ & $175(120-300)$ & 0.79 \\
\hline Neonatal outcome & $n=45$ & $n=36$ & \\
\hline Stillbirth & $6(14 \%)$ & $1(3 \%)$ & 0.10 \\
\hline Child alive, Apgar Score of $<7$ at $5^{\prime}$ & $1(2 \%)$ & $1(3 \%)$ & 0.69 \\
\hline $\begin{array}{l}\text { Adverse neonatal outcome } \\
\text { (stillbirth or Apgar Score }<7 \text { at 5) }\end{array}$ & $7(16 \%)$ & $2(6 \%)$ & 0.14 \\
\hline \multicolumn{4}{|l|}{ Characteristics at 1 st CS } \\
\hline Uterotomy closure in 2 layers & $59 \%(19 / 32)$ & $71 \%(15 / 21)$ & 0.55 \\
\hline Transverse incision & $35 \%(15 / 43)$ & $62 \%(21 / 34)$ & 0.03 \\
\hline Closure visceral peritoneum & $59 \%(19 / 32)$ & $53 \%(16 / 30)$ & 0.82 \\
\hline Closure rectus muscles & $16 \%(5 / 32)$ & $20 \%(4 / 20)$ & 0.72 \\
\hline Wound infection & $14 \%(3 / 22)$ & $6 \%(1 / 16)$ & 0.62 \\
\hline
\end{tabular}

condition at discharge; there is no long-term follow up or registration of perinatal mortality. Strengths of this study are both the relatively high number of patients and information at the level of rural district hospitals in an LIC, which allowed us to compare local outcomes to larger studies in the literature.

\section{Conclusion}

This retrospective study provides insight into the practice of repeat CS in a rural hospital in an LIC. Adhesions after CSs are common and occur more frequently after midline skin incision. No effect of closure of the peritoneum on adhesion formation was observed. Adverse neonatal outcomes were not statistically significantly more common when severe adhesions were present. Audit of local data is important to evaluate the quality of care and to relate local outcomes to the literature.

\section{Abbreviations}

CS: Caesarean section; HIC: High-income country; LIC: Low-income country; RCT: Randomized controlled trial; TFR: Total fertility rate; TOL: Trial of labour; UR: Uterine rupture; VBAC: Vaginal birth after caesarean section

\section{Acknowledgements}

Not applicable.

\section{Authors' contributions}

RM and JS were involved in the conception and design of the study. RM did the fieldwork, data management, carried out the analysis and wrote the first draft of the paper. RM, IM, JVD and JS assisted in the interpretation of the data and writing of the manuscript. All authors read and approved the final draft of the paper.

\section{Funding}

No funding has been obtained during the study period. Financial support to cover the Article Processing Charges has been granted by the current institutions of RM, JS and JVD. This occurred after the study had been completed and the manuscript was written.

Availability of data and materials

Data are available from the author upon request.

\section{Ethics approval and consent to participate}

All data were anonymously collected after discharge of the patient and were written down by the health workers as part of routine care. No written informed consent was obtained from patients. The data could not be traced back to an individual patient. Written permission and ethical clearance were obtained from the medical officer in charge, the district medical officer and the directorate of research and publications of the University of Dodoma (ref. UDOM/DRP/346).

\section{Consent for publication}

Not applicable.

\section{Competing interests}

The authors declare that they have no competing interest.

\section{Author details}

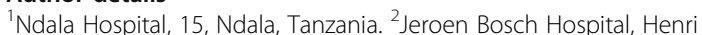
Dunantstraat 1, $5223 \mathrm{GZ}$ 's-Hertogenbosch, The Netherlands. ${ }^{3} \mathrm{College}$ of Health Sciences, University of Dodoma, 395, Dodoma, Tanzania. ${ }^{4}$ Radboud University Medical Centre, Geert Grooteplein-Zuid 10, 6525 GA Nijmegen, The Netherlands. ${ }^{5}$ Leeuwarden Medical Centre, Henri Dunantweg 2, 8934 AD Leeuwarden, The Netherlands. 'University Medical Centre Groningen/ University of Groningen, Antonius Deusinglaan 1, 9700 AD Groningen, The Netherlands.

Received: 25 November 2018 Accepted: 1 September 2020 Published online: 04 October 2020

References

1. Boerma T, Ronsmans C, Melesse DY, Barros AJD, Barros FC, Juan L, Moller $A B$, Say L, Hosseinpoor AR, Yi M, et al. Global epidemiology of use of and disparities in caesarean sections. Lancet. 2018;392(10155):1341-8.

2. Betran AP, Ye J, Moller AB, Zhang J, Gulmezoglu AM, Torloni MR. The increasing trend in caesarean section rates: global, regional and national estimates: 1990-2014. PLoS One. 2016;11(2):e0148343.

3. WHO. Health Situation Analysis in the African Region. Atlas of Health Statistics. Brazzaville/Republic of Congo: World Health Organization. Regional Office for Africa; 2011.

4. Boatin AA, Agaba E, Nyongozi B, Wylie BJ. Stage of labor at admission among Ugandan women with a prior cesarean, and its impact on management and delivery outcomes. Int J Gynaecol Obstet. 2017;139(1):14-20.

5. Mola G, Verkuyl DA. To VBAC or not to VBAC. Bjog. 2014;121(7):908.

6. van Roosmalen J, van den Akker T. Safety concerns for caesarean section. Bjog. 2014;121(7):909-10

7. Wanyonyi SZ, Ngichabe SK. Safety concerns for planned vaginal birth after caesarean section in sub-Saharan Africa. Bjog. 2014;121(2):141-3 discussion 144

8. Kabore C, Chaillet N, Kouanda S, Bujold E, Traore M, Dumont A. Maternal and perinatal outcomes associated with a trial of labour after previous caesarean section in sub-Saharan countries. Bjog. 2015. 
9. Bishop D, Dyer RA, Maswime S, Rodseth RN, van Dyk D, Kluyts HL, Tumukunde JT, Madzimbamuto FD, Elkhogia AM, Ndonga AKN, et al. Maternal and neonatal outcomes after caesarean delivery in the African surgical outcomes study: a 7-day prospective observational cohort study. Lancet Glob Health. 2019;7(4):e513-22.

10. Sobhy S, Arroyo-Manzano D, Murugesu N, Karthikeyan G, Kumar V, Kaur I, Fernandez E, Gundabattula SR, Betran AP, Khan K, et al. Maternal and perinatal mortality and complications associated with caesarean section in low-income and middle-income countries: a systematic review and metaanalysis. Lancet. 2019;393(10184):1973-82.

11. Guise JM, Denman MA, Emeis C, Marshall N, Walker M, Fu R, Janik R, Nygren $P$, Eden KB, McDonagh M. Vaginal birth after cesarean: new insights on maternal and neonatal outcomes. Obstet Gynecol. 2010;115(6):1267-78.

12. van Roosmalen J. Vaginal birth after cesarean section in rural Tanzania. Int J Gynaecol Obstet. 1991;34(3):211-5.

13. Aisien $\mathrm{AO}$, Oronsaye $\mathrm{AU}$. Vaginal birth after one previous caesarean section in a tertiary institution in Nigeria. J Obstet Gynaecol. 2004;24(8):886-90.

14. Lower AM, Hawthorn RJ, Clark D, Boyd JH, Finlayson AR, Knight AD, Crowe AM. Adhesion-related readmissions following gynaecological laparoscopy or laparotomy in Scotland: an epidemiological study of 24046 patients. Hum Reprod. 2004:19(8):1877-85.

15. Marshall NE, Fu R, Guise JM. Impact of multiple cesarean deliveries on maternal morbidity: a systematic review. Am J Obstet Gynecol. 2011;205(3): 262 e261-8

16. Hill JB, Ammons A, Chauhan SP. Vaginal birth after cesarean delivery: comparison of ACOG practice bulletin with other national guidelines. Clin Obstet Gynecol. 2012;55(4):969-77.

17. Olagbuji B, Ezeanochie M, Okonofua F. Predictors of successful vaginal delivery after previous caesarean section in a Nigerian tertiary hospital. J Obstet Gynaecol. 2010;30(6):582-5.

18. Spaans WA, van der Velde FH, van Roosmalen J. Trial of labour after previous caesarean section in rural Zimbabwe. Eur J Obstet Gynecol Reprod Biol. 1997;72(1):9-14

19. Shi Z, Ma L, Yang Y, Wang H, Schreiber A, Li X, Tai S, Zhao X, Teng J, Zhang $L$, et al. Adhesion formation after previous caesarean section-a meta-analysis and systematic review. BJOG. 2011;118(4):410-22

20. Bamigboye AA, Hofmeyr GJ. Closure versus non-closure of the peritoneum at caesarean section: short- and long-term outcomes. Cochrane Database Syst Rev. 2014;8:Cd000163.

21. Tanzania Demographic and Health Survey 2010. In. Dar es Salaam, Tanzania and Calverton, Maryland: National Bureau of Statistics (NBS) and ICF Macro; 2011.

22. Tanzania Demographic and Health Survey and Malaria Indicator Survey 2015-2016. In. Dar es Salaam, Tanzania and Calverton, Maryland: Ministry of Health, Community Development, Gender, Elderly and Children, National Bureau of Statistics (NBS) and ICF Macro; 2016

23. Practice Bulletin No. 184; Vaginal birth after cesarean delivery. Obstet Gynecol 2017, 130(5):e217-e233.

24. ACOG Committee Opinion. Number 333, May 2006 (replaces No. 174, July 1996): the Apgar score. Obstet Gynecol. 2006;107(5):1209-12.

25. Boatin AA, Adu-Bonsaffoh K, Wylie BJ, Obed SA. Evaluating facility-based decision-making in women with a prior cesarean delivery and association with maternal and perinatal outcomes. Matern Child Health J. 2017;21(9): 1845-52.

26. van Duinen AJ, Westendorp J, Kamara MM, Forna F, Hagander L, Rijken MJ, Leather A, Wibe A, Bolkan HA. Perinatal outcomes of cesarean deliveries in Sierra Leone: a prospective multicenter observational study. Int J Gynaecol Obstet. 2020.

27. Nuamah MA, Browne JL, Ory AV, Damale N, Klipstein-Grobusch K, Rijken MJ. Prevalence of adhesions and associated postoperative complications after cesarean section in Ghana: a prospective cohort study. Reprod Health. 2017; 14(1):143.

28. Myers SA, Bennett TL. Incidence of significant adhesions at repeat cesarean section and the relationship to method of prior peritoneal closure. J Reprod Med. 2005;50(9):659-62.

29. Sikirica V, Broder MS, Chang E, Hinoul P, Robinson D, Wilson M. Clinical and economic impact of adhesiolysis during repeat cesarean delivery. Acta Obstet Gynecol Scand. 2012;91(6):719-25.

30. Greenberg MB, Daniels K, Blumenfeld YJ, Caughey AB, Lyell DJ. Do adhesions at repeat cesarean delay delivery of the newborn? Am J Obstet Gynecol. 2011;205(4):380.e381-5.
31. Shenhav S, Grin L, Kapustian V, Anteby EY, Gdalevich M, Gemer O. Quantifying the effects of postcesarean adhesions on incision to delivery time. J Matern Fetal Neonatal Med. 2018:1-6.

32. Walfisch A, Beloosesky R, Shrim A, Hallak M. Adhesion prevention after cesarean delivery: evidence, and lack of it. Am J Obstet Gynecol. 2014; 211(5):446-52

33. Plante B, Sukalich S, Elliott JO. Adhesion assessment at first repeat caesarean section with or without prior adhesion barrier use. J Obstet Gynaecol Can. 2016:38(9):795-803.

34. Abalos E, Addo V, Brocklehurst P, El Sheikh M, Farrell B, Gray S, Hardy P, Juszczak E, Mathews JE, Naz Masood S, et al. Caesarean section surgical techniques: 3 year follow-up of the CORONIS fractional, factorial, unmasked, randomised controlled trial. Lancet. 2016;388(10039):62-72.

35. Caesarean section surgical techniques: a randomised factorial trial (CAES AR)*. BJOG. 2010;117(11):1366-1376.

36. Sholapurkar SL. Can the practice of nonclosure of visceral and parietal peritoneum during cesarean delivery be justified? Am J Obstet Gynecol. 2015;212(4):550

37. Maaloe N, Aabakke AJ, Secher NJ. Midline versus transverse incision for cesarean delivery in low-income countries. Int J Gynaecol Obstet. 2014; 125(1):1-2.

38. Hofmeyr GJ, Mathai M, Shah A, Novikova N. Techniques for caesarean section. Cochrane Database Syst Rev. 2008;(1):Cd004662.

39. World Health Organization U, UNICEF, World Bank. Integrated Management of Pregnancy and Childbirth. Managing complications in pregnancy and childbirth: a guide for midwives and doctors. 2007

40. Ansaloni L, Brundisini R, Morino G, Kiura A. Prospective, randomized, comparative study of Misgav Ladach versus traditional cesarean section at Nazareth Hospital, Kenya. World J Surg. 2001;25(9):1164-72.

41. Grantcharov TP, Rosenberg J. Vertical compared with transverse incisions in abdominal surgery. Eur J Surg. 2001;167(4):260-7.

42. Hesselman S, Hogberg U, Rassjo EB, Schytt E, Lofgren M, Jonsson M. Abdominal adhesions in gynaecologic surgery after caesarean section: a longitudinal population-based register study. Bjog. 2018;125(5):597-603.

43. Lyell DJ, Caughey AB, Hu E, Daniels K. Peritoneal closure at primary cesarean delivery and adhesions. Obstet Gynecol. 2005;106(2):275-80.

\section{Publisher's Note}

Springer Nature remains neutral with regard to jurisdictional claims in published maps and institutional affiliations.
Ready to submit your research? Choose BMC and benefit from:

- fast, convenient online submission

- thorough peer review by experienced researchers in your field

- rapid publication on acceptance

- support for research data, including large and complex data types

- gold Open Access which fosters wider collaboration and increased citations

- maximum visibility for your research: over $100 \mathrm{M}$ website views per year

At $\mathrm{BMC}$, research is always in progress.

Learn more biomedcentral.com/submissions 